\title{
ASSESS THE READINESS OF THE OUTPATIENT TREATMENT CENTERS OF SOCIAL SECURITY TO RUN SMART HEALTH CARD
}

\section{Type of article: conference abstract}

Marziyhe Meraji 1, mehdi esmaeilzadhe 2, Mohammadreza Motiee 3, Sanaz sadat mahmoodian4*

1: Assistant Professor, Department of Medical Records and Health Information Technology, School of Paramedical Sciences, Mashhad University of Medical Sciences and Health Services, Mashhad, Iran

2: B.Sc. in Medical Records, Department of Medical Records and Health Information

Technology, School of Paramedical Sciences, Mashhad University of Medical Sciences and Health Services, Mashhad, Iran

3: B.Sc. in Medical Records, the Iranian Social Security Organization, Mashhad, Iran 4:MSc in Medical Records, Department of Medical Records and Health Information Technology, School of Paramedical Sciences, Mashhad University of Medical Sciences and Health Services, Mashhad, Iran

*Tel: +989153201550-, E-mail: :mahmoudians2@mums.ac.ir

\begin{abstract}
Introduction: Smart card, microprocessor chip, facilitate providing e-health services in health center. Design and implementation of smart cards in the Social Security Organization as one of the health centers reduce costs, prevent abuses of medical insurance, increase productivity and accelerate response time. In this study, readiness of the outpatient treatment centers of social security to implement health smart card assessed.

Methods: this practical and descriptive study was conducted in nine outpatient treatment center of Khorasan Razavi Social Security center in 2016-2017. Total proposed number of outpatient treatment center was reduced to 9 center because other centers did not take part in this review.A questionnaire with three areas of technical readiness, organizational culture and leadership and management was used. The data were analyzed using spss 19 software

Results: Finding showed Average scores of technical and leadership and cultural organization readiness were ordinary in all centers. Leadership and cultural organization readiness in 4 center were more than others. Average scores of technical were more than of leadership and cultural organization readiness.Technical readiness had significant difference between the studied centers. Conclusion: Finding showed appropriate technical readiness in Social Security, therefore we suggest to implement smart cards, educating staff to enhance technology skills and to promote its use culture. Readiness of management and leadership scope is impressive in designing and implementing smart cards; So implementing smart cards should be organization`s strategy and the road map should be determined, and its benefits should be clearly explain for social security center managers.
\end{abstract}

KEYWORDS: Outpatient, Social Security, Smart Card.

\section{Declaration of conflicts}

This abstract is selected from the First International Congress of Diseases and Health Outcomes Registry and First National Congress of Medical Informatics, 14-17 February 2017, Mashhad, Iran

\section{Authors' biography}

No biography. 
Medical Technologies Journal, Volume: 1, Issue: 4, October-December 2017, Pages:76-136. Doi : https://doi.org/10.26415/2572-004X-vol1iss4

\section{References}

No references. 